\title{
Single nucleotide polymorphisms in DNA repair genes and risk of cervical cancer: A case-control study
}

\author{
LIHUA ZHANG $^{1 *}$, ZHENCHAO RUAN $^{2 *}$, QINGYA HONG $^{3}$, XIANGZHEN GONG $^{4}$, \\ ZHENGGUANG $\mathrm{HU}^{4}$, YAN HUANG ${ }^{2}$ and AIDI $\mathrm{XU}^{5}$ \\ ${ }^{1}$ Department of Radiation Oncology, Cancer Hospital, Fudan University, Shanghai 200032; \\ ${ }^{2}$ State Key Laboratory of Genetic Engineering, Institute of Genetics, School of Life Sciences, \\ Fudan University, Shanghai 200433; ${ }^{3}$ Hospital of Obstetrics and Gynecology, Attached Fudan University, \\ Shanghai 200011; ${ }^{4}$ Hongkou Maternal and Child Health Care Institute, Shanghai 200437; \\ ${ }^{5}$ Shanghai Hongkou District Health Bureau, Shanghai 200437, P.R. China
}

Received May 27, 2011; Accepted September 27, 2011

DOI: $10.3892 / \mathrm{ol} .2011 .463$

\begin{abstract}
In this report, we describe a case control study in a Chinese population aimed at identifying possible associations between susceptibility to cervical cancer and single nucleotide polymorphisms in XRCC1 $194 \mathrm{C}>\mathrm{T}, \mathrm{XRCCl} 280 \mathrm{G}>\mathrm{A}, \mathrm{XRCC1}$ 399G $>\mathrm{A}$, ERCC2 751A $>\mathrm{C}$, ERCC2 156C $>\mathrm{A}$, ERCC1 118C $>\mathrm{T}$, $P A R P 1762 \mathrm{~T}>\mathrm{C}, R A D 51135 \mathrm{G}>\mathrm{C}$ and HER2 655A $>\mathrm{G}$. The cases comprised 154 patients: 80 cervical squamous cell carcinomas (SCCs), 2 adenocarcinomas and 72 cervical intraepithelial neoplasias (CINs). A total of 177 healthy women were recruited as the controls. A significant association was found between ERCC1 $118 \mathrm{C}>\mathrm{T}$ and $\mathrm{SCC}$ in the additive genetic model [odds ratio $(\mathrm{OR})=1.711 ; 95 \%$ confidence interval (CI), 1.089-2.880; $\mathrm{p}=0.021]$ and the dominant genetic model (OR=1.947; 95\% CI, 1.056-3.590; $\mathrm{p}=0.033)$. Among women with a smoking family member, ERCC1 $118 \mathrm{C}>\mathrm{T}$ increased SCC risk in the additive model $(\mathrm{OR}=2.800 ; 95 \% \mathrm{CI}$, 1.314-5.968; $\mathrm{p}=0.008$ ). For women who had first intercourse before 22 years of age, XRCC1 $280 \mathrm{G}>\mathrm{A}$ was found to act as a protective factor for $\mathrm{SCC}$ under the additive model $(\mathrm{OR}=0.228$; 95\% CI, 0.058-0.900; $\mathrm{p}=0.035)$, while $R A D 51$ 135G $>\mathrm{C}$ was a risk factor for CIN (OR=4.246; 95\% CI, 1.335-13.502; $\mathrm{p}=0.014)$. For women who had first intercourse after 22 years
\end{abstract}

Correspondence to: Dr Yan Huang, Institute of Genetics, School of Life Sciences, Fudan University, Room 604 Science Building, 220 Handan Road, Shanghai 200433, P.R. China

E-mail: huangyan@fudan.edu.cn

Professor Aidi Xu, Shanghai Hongkou District Health Bureau, 76 Feihong Rd., Shanghai 200086, P.R. China

E-mail: helenxu602003@yahoo.com.cn

${ }^{*}$ Contributed equally

Key words: cervical cancer, cervical intraepithelial neoplasia, single nucleotide polymorphism, association study, squamous cell carcinoma of age, the additive genetic model showed $R A D 51135 \mathrm{G}>\mathrm{C}$ $(\mathrm{OR}=0.359 ; 95 \% \mathrm{CI}, 0.138-0.934 ; \mathrm{p}=0.036)$ and $H E R 2$ 655A $>\mathrm{G}$ $(\mathrm{OR}=0.309 ; 95 \% \mathrm{CI}, 0.098-0.972 ; \mathrm{p}=0.045)$ to be protective factors for SCC. XRCC1 399G >A increased CIN risk among women who first gave birth before the age of 22 in the additive genetic model $(\mathrm{OR}=4.459$; 95\% CI, 1.139-17.453; $\mathrm{p}=0.032)$. For those who first gave birth after age 22, ERCC1 118C >T was found to be a risk factor for SCC in the additive genetic model $(\mathrm{OR}=1.884 ; 95 \% \mathrm{CI}, 1.088-3.264 ; \mathrm{p}=0.024)$. A significant interaction was observed between $R A D 51$ 135G $>\mathrm{C}$ and age at first intercourse $\left(\mathrm{p}_{\text {interaction }}=0.033\right.$ for $\mathrm{SCC}, \mathrm{p}_{\text {interaction }}=0.021$ for CIN), as well with sexual partner number $\left(\mathrm{p}_{\text {interaction }}=0.001\right.$ for SCC). The interaction between $H E R 2655 \mathrm{~A}>\mathrm{G}$ and age at first intercourse, ERCC2 $156 \mathrm{C}>\mathrm{A}$ and family smoking status and XRCC1 $280 \mathrm{G}>\mathrm{A}$ and alcohol consumption were significant, with $\mathrm{p}_{\text {interaction }}=0.023$ for SCC, $\mathrm{p}_{\text {interaction }}=0.021$ for CIN and $\mathrm{p}_{\text {interaction }}=0.025$ for SCC, respectively.

\section{Introduction}

Cervical cancer ranks as the second most common female-related cancer worldwide, following breast cancer. Squamous cell carcinoma (SCC), adenocarcinoma (ADC), and adenosquamous cell carcinoma (ADSC) are the three most common histological subtypes of cervical cancer. Screening programs in developed countries have reduced the incidence and prevalence of cervical cancer in these areas, but developing countries often do not have the resources for these programs (1). The result is that $80 \%$ of cervical cancer cases now occur in developing countries (2).

In China, incidence rates of cervical cancer range from 2.4 to 4.6 per 100,000 women (3), and the mortality rates range from 2 to 4 per 100,000 women in urban areas. Various evidence has shown that certain types of the oncogenic virus human papillomavirus (HPV) are closely related to the occurrence of cervical cancer (4) and its precursor lesion cervical intraepithelial neoplasia (CIN) (5). However, only a small portion of women go on to develop cervical cancer following infection with HPV (6), and this suggests that other factors, 
including genetic susceptibility, may also contribute to cervical cancer.

An association between smoking and cervical cancer has been reported (7), as well as smoking-related DNA damage in the cervical epithelium (8). Defects in DNA repair pathways relate to a number of diseases including cancer, and the significance of DNA repair mechanisms in genetic stability maintenance is well accepted in the protection against cancer initiation (9).

There are a number of different types of DNA repair pathways; for single-strand breaks, these include the base excision repair (BER) and nucleotide excision repair (NER) systems and for double-strand DNA breaks, there are two principle mechanisms: homologous recombination (HR) and non-homologous end joining (NHEJ) (10). There are a number of genes known to be involved in these pathways. For example, it is known that the genes, ERCC1 and ERCC2, code for proteins involved in the NER system, removing bulky lesions from DNA caused by things such as toxic chemicals or ultraviolet light $(11,12)$. Two other genes, XRCC1 and PARPI, are crucial to BER systems, which repair DNA damage due to causes such as ionizing radiation. PARP1 is also known to signal damage to other repair mechanisms (12,13). RAD51 functions in the DNA repair of double-strand breaks by HR mechanisms (10). It is also notable that these genes have been implicated in response (or non-response) to certain types of chemotherapeutic drugs (14).

A single nucleotide polymorphism (SNP) is a single nucleotide change in a DNA sequence between two individuals. Knowledge of the genes involved in these DNA repair mechanisms is enlightening investigators and enabling the study of the association between SNPs in these genes and the likelihood of developing cancer (15).

The associations of SNPs in DNA repair genes and various types of cancer and tumors have been extensively described. However, the evidence is frequently confusing, with some SNPs increasing the risk of certain types of cancer, but decreasing the risk of others. For example, previous studies have reported that XRCC1 Arg194Trp C>T (TT) increases the risk of esophageal (16) and bile duct cancer (17), but decreases the risk of gastric carcinoma (18). XRCC1 Arg280His G $>$ A has been reported as a risk factor for breast cancer (19) and as a protective factor for bile duct cancer (17). Niwa et al (20) first reported that the XRCC1 Arg399GIn G>A polymorphism is related to the increased susceptibility to cervical cancer in a Japanese population.

We performed a case-control study, in a Chinese population, of eight SNPs from the DNA repair-related genes, $E R C C 1, E R C C 2, X R C C 1, P R A P 1$ and $R A D 51$, as well as one SNP in HER2, which plays essential roles in stabilizing the active protein dimer.

\section{Materials and methods}

Study subjects. All subjects were genetically unrelated ethnic Han Chinese from Shanghai in eastern China. Patients diagnosed with histopathologically confirmed cervical cancer or CIN were consecutively recruited between June 2006 and May 2008 at the Margaret Willianson Hospital, Hongkou Maternal and Child Care Service Centre, and the Gynecology Department of Jiangwan Hospital, without restrictions on age
Table I. Primers for single nucleotide polymorphism detection.

$\begin{array}{cl}\text { rs } 1136410 & \\ \text { 5' primer } & \text { TGAGCAGACTGTAGGCCAC } \\ \text { 3' primer } & \text { TCTGTCTCATTCACYATGATACCTA } \\ \text { Ext primer } & \text { CGACTGTAGGTGCGTAACTCGTCC } \\ & \text { AGCAGGTTGTCAAGCATTTCC }\end{array}$

rs 1801200

5 ' primer

3' primer

Ext primer

AAACTAGCCCTCAATCCCTG

AAAGACCACCCCCAAGAC

rs 1799782

5 ' primer

3' primer

Ext primer

AGAGCGAGTGACGCATACTACGCCCCC AGCCCTCTGACGTCCRTC

\section{rs 11615 \\ 5 ' primer \\ 3' primer \\ Ext.primer}

TYAGGACCCAYGTTGTCC
ATGAGAGCGCCAACTCTCT

AGATAGAGTCGATGCCAGCTTCACCTG GRGATGTCTTGTTGATCC

rs 13181

5 ' primer

3' primer

Ext primer

TTCGTCCCTCCCCAGAGG

ATGAGAGCGCCAACTCTCT

GTGATTCTGTACGTGTCGCCTTACGTC

GCCAAATTCCCAGGGCAC

rs25489

5 ' primer

3' primer

Ext primer

CTGTCCCTGCTCAGCCTG

AAGACTCAGGAGTCACCAGGA

AGGGTCTCTACGCTGACGATGCTAGAA

TCAGAGGAGACGCTG

rs 1801320

5 ' primer

3' primer

Ext primer

TTGACCCCCAGTGGTGCTA

TGTCACTGCCCCCTGTGC

GGCTATGATTCGCAATGCTTTCTTCTC

CAGTGCCAGCTCCAACTC

rs 25487

5 ' primer

3' primer

AACTGCAACTCATCTGGGTT

TCCTCTCTCCAGCAGGCC

GCGGTAGGTTCCCGACATATGAGTAGA

GAAGTGGAGCGTAAGCCA

Ext primer

TAAGGAGTGGGTGCTGGA

ATTGCCCAGCACAGGATA

AGCGATCTGCGAGACCGTATCGCATGC GTCGGCGGCTGCCCTCCC

rs238406

5 ' primer

3' primer

TATGTGCGGGCGCAGTAC

Ext primer

CGTGCCGCTCGTGATAGAATATGACAC CAGCCTGCCCCACTGCCG

Ext, extension.

and histology. The exclusion criteria included self-reported cancer history, previous radiotherapy and chemotherapy for unknown disease conditions and a family history of cancer. The controls were recruited during the same period from health examinees at the Hongkou Maternal and Child Care 
Table II. Distributions of demographic characters in the study population.

\begin{tabular}{|c|c|c|c|c|c|}
\hline \multirow[b]{2}{*}{ Variable } & \multirow{2}{*}{$\begin{array}{c}\text { Controls } \\
(n=177) \text { no. }(\%)\end{array}$} & \multicolumn{2}{|c|}{ CIN } & \multicolumn{2}{|l|}{ SCC } \\
\hline & & $(n=72)$ no. $(\%)$ & $\mathrm{p}$-value ${ }^{\mathrm{b}}$ & $(\mathrm{n}=80)$ no. $(\%)$ & $\mathrm{p}$-value ${ }^{\mathrm{b}}$ \\
\hline Age & $43(24-55)^{\mathrm{a}}$ & $40(24-59)^{\mathrm{a}}$ & & $44(26-79)^{\mathrm{a}}$ & \\
\hline \multicolumn{6}{|l|}{ Education level } \\
\hline$\leq$ Junior high school & $64(36.2)$ & $28(38.9)$ & 0.772 & $29(36.2)$ & 1.000 \\
\hline$\geq$ Senior high school & $113(63.8)$ & $44(61.1)$ & & $51(63.8)$ & \\
\hline \multicolumn{6}{|l|}{ Smoking status } \\
\hline No & $167(94.4)$ & $72(100)$ & 0.067 & $76(95.0)$ & 1.000 \\
\hline Yes & $10(5.6)$ & 0 & & $4(5.0)$ & \\
\hline \multicolumn{6}{|l|}{ Alcohol consumption } \\
\hline No & $148(83.6)$ & $63(87.5)$ & 0.561 & $73(91.2)$ & 0.122 \\
\hline Yes & $29(16.4)$ & $9(12.5)$ & & $7(8.8)$ & \\
\hline \multicolumn{6}{|l|}{ Family smoking status } \\
\hline No & $61(34.5)$ & $47(65.3)$ & 0 & $46(57.5)$ & 0.001 \\
\hline Yes & $116(65.5)$ & $25(34.7)$ & & $34(42.5)$ & \\
\hline \multicolumn{6}{|l|}{$\begin{array}{l}\text { Number of sexual } \\
\text { partners }\end{array}$} \\
\hline$\leq 1$ & $144(81.4)$ & $50(73.5)$ & 0.218 & $62(81.6)$ & 1.000 \\
\hline$>1$ & $33(18.6)$ & $18(26.5)$ & & $14(18.4)$ & \\
\hline \multicolumn{6}{|l|}{ Age at first intercourse } \\
\hline$\leq 22$ & $37(20.9)$ & $28(41.8)$ & 0.002 & $38(51.4)$ & 0 \\
\hline$>22$ & $140(79.1)$ & $39(58.2)$ & & $36(48.6)$ & \\
\hline \multicolumn{6}{|l|}{ Age at first childbirth } \\
\hline$\leq 22$ & $24(13.6)$ & $13(19.4)$ & 0.317 & $19(25.0)$ & 0.030 \\
\hline$>22$ & $153(86.4)$ & $54(80.6)$ & & $57(75.0)$ & \\
\hline
\end{tabular}

${ }^{a}$ Mean (minimum-maximum). ${ }^{b}$ Fisher's exact test. CIN, cervical intraepithelial neoplasia; SCC, squamous cell carcinoma.

Service Centre. The controls were healthy women whose sexual history and age matched the cases, and who were histologically or cytologically diagnosed as having a normal cervix or chronic cervicitis, with no personal or familial history of cancer or other family genetic diseases.

Questionnaire. All patients underwent a complete medical history interview at entry. Detailed information regarding demographic factors (including age at diagnosis, education level, number of sexual partners, age at first intercourse and age at first childbirth), occupational history, environmental exposure data (including tobacco smoking status, alcohol consumption and family smoking status) and family history of cancer were also included. Those who had smoked less than one cigarette per day for a period of one year or less were defined as non-smokers, and the rest were considered to have always smoked. Alcohol consumption was defined as 'no' if the participant drank alcohol less than once per week, but otherwise was regarded as 'yes'. Family smoking status was 'no' for participants who had no family member who smoked in the home, but was otherwise regarded as 'yes'. Family history of cancer was defined as any self-reported cancer in first-degree relatives. Following the interview, approximately $2 \mathrm{ml}$ of venous blood was collected from each participant and maintained below $-40^{\circ} \mathrm{C}$.
Laboratory methods. Genetic DNA was extracted from peripheral blood by the standard phenol-chloroform procedure. SNP genotyping was conducted with the SNPware 12plex assay using the SNPstream ${ }^{\mathrm{TM}}$ system (Beckman Coulter, Inc., Brea, CA, USA). The amplifying and extension primers are shown in Table I. The nine SNPs were: XRCC1 194C >T (rs1799782), XRCC1 280G $>\mathrm{A}$ (rs25489), XRCC1 399G $>\mathrm{A} \quad(\mathrm{rs} 25487)$, ERCC2 751A $>\mathrm{C} \quad$ (rs13181), ERCC2 156C >A (rs238406), ERCC1 118C >T (rs11615), PARP1 762T >C (rs1136410), RAD51 $135 \mathrm{G}>\mathrm{C}(\mathrm{rs} 1801320)$ and HER2 655A $>\mathrm{G}(\mathrm{rs} 1801200)$.

Genotyping was performed according to the manufacturer's instructions. Briefly, multiple polymerase chain reaction (PCR) was performed with the following program: $94^{\circ} \mathrm{C}$ for $1 \mathrm{~min}$, then $94^{\circ} \mathrm{C}$ for $30 \mathrm{sec}, 55^{\circ} \mathrm{C}$ for $30 \mathrm{sec}$ and $72^{\circ} \mathrm{C}$ for $1 \mathrm{~min}$, for 39 cycles. The PCR product was used for SNP extension: $96^{\circ} \mathrm{C}$ for $3 \mathrm{~min}$, then $94^{\circ} \mathrm{C}$ for $20 \mathrm{sec}$ and $40^{\circ} \mathrm{C}$ for $11 \mathrm{sec}$, for 45 cycles. A chip hybridization reaction was conducted at $42^{\circ} \mathrm{C}$ for $2 \mathrm{~h}$ with hybridization solution and hybridization additive solution at the proportion of 18:1. Chip data were scanned and analyzed using the SNPstream machine (Beckman Coulter, Inc.).

Statistical analysis. To examine the Hardy-Weinberg equilibrium, a $\chi^{2}$ goodness-of-fit test was performed using a web-based program (http://ihg2.helmholtz-muenchen.de/ cgi-bin/hw/hwal.pl). The frequency distribution of education, 


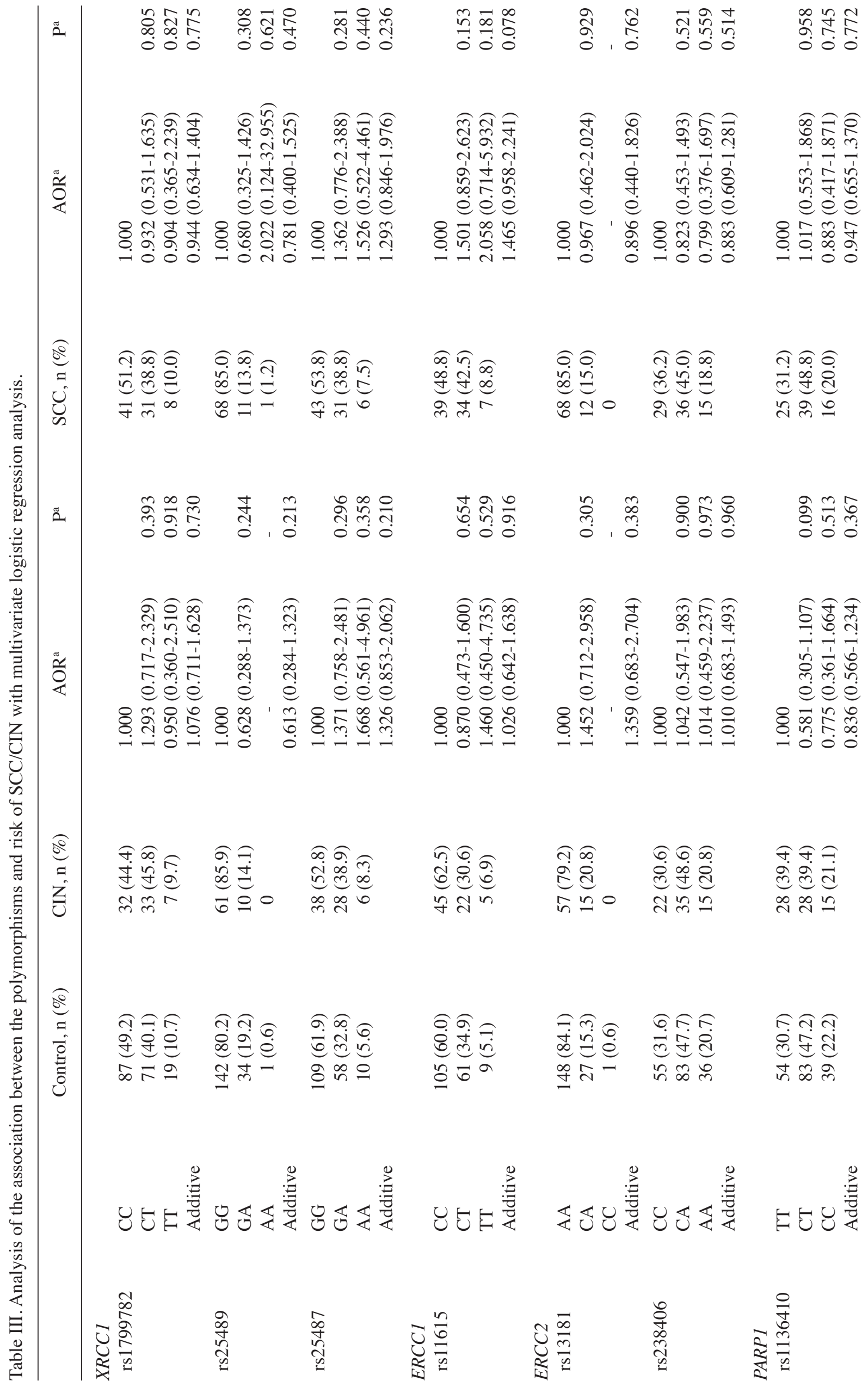


smoking status, alcohol consumption, family smoking status, number of sexual partners, age at first intercourse and age at first childbirth was compared between the controls and CIN/ SCC cases using Fisher's exact $\chi^{2}$-test. Odds ratios (ORs) and 95\% confidence intervals (CIs) were calculated by univariate logistic regression analyses and multivariate logistic regression analyses adjusted for age, family smoking status, age at first intercourse and age at first childbirth under the dominant genetic, recessive genetic and additive model. The subjects were stratified according to family smoking status, age at first intercourse, age at first childbirth and disease subtypes, in order to estimate specific ORs and CIs.

Interaction between the nine SNPs and demographic factors (family smoking status, age at first intercourse, age at first childbirth, sexual partner number and alcohol consumption) were estimated. All the regression analyses were performed using SPSS 16.0 software (SPSS Inc., Chicago, IL, USA). Quanto (version 1.2.4) software was used to calculate the statistical power. All p-values were two-sided, and $\mathrm{p}<0.05$ was considered to be statistically significant.

\section{Results}

Characteristics of the study population. A total of 154 patients (82 carcinomas and 72 CINs) and 177 cancer-free controls were enrolled in the study. Among all carcinomas, two patients were diagnosed with ADC and the rest were diagnosed with SCC. Thus, our study focused on SCC and CIN. The characteristics of the study participants are shown in Table II. There was no significant difference in age between controls and patients with CIN/SCC. Similarly, education level, smoking status, alcohol consumption and the number of sexual partners were not significantly associated with CIN or SCC risk. However, significant differences between the cases and controls were found in family smoking status, age at first intercourse and age at first childbirth. These factors have previously been reported as risk factors for HPV infection, or co-factors for cervical cancer (3).

Association between SNPs and risk of cervical SCC and CIN. The genotype distributions of controls were in Hardy-Weinberg equilibrium (data not shown). No SNP was found to be associated with the risk of SCC or CIN in all the subjects in the univariate logistic regression analyses (data not shown). Table III shows the adjusted association of the nine SNPs in the two case groups. In the dominant genetic model, a significantly increased risk of SCC was observed in ERCC1 $118 \mathrm{C}>\mathrm{T}$ (OR=1.947; 95\% CI, 1.056-3.590; $\mathrm{p}=0.033$ ) when adjusted for age, family smoking status, age at first intercourse and age at first childbirth. The effect was more clear when the additive model was applied (OR=1.771; 95\% CI, 1.089-2.880; $\mathrm{p}=0.021$ ).

The statistical powers of the dominant, recessive and additive model were evaluated for each SNP, and the additive model was found to have the highest statistical power in the study (data not shown). Thus, an additive model was used for all the following association analyses.

Association analysis following stratification. Significant distribution differences between the controls and cases were found in family smoking status, age at first intercourse and age 


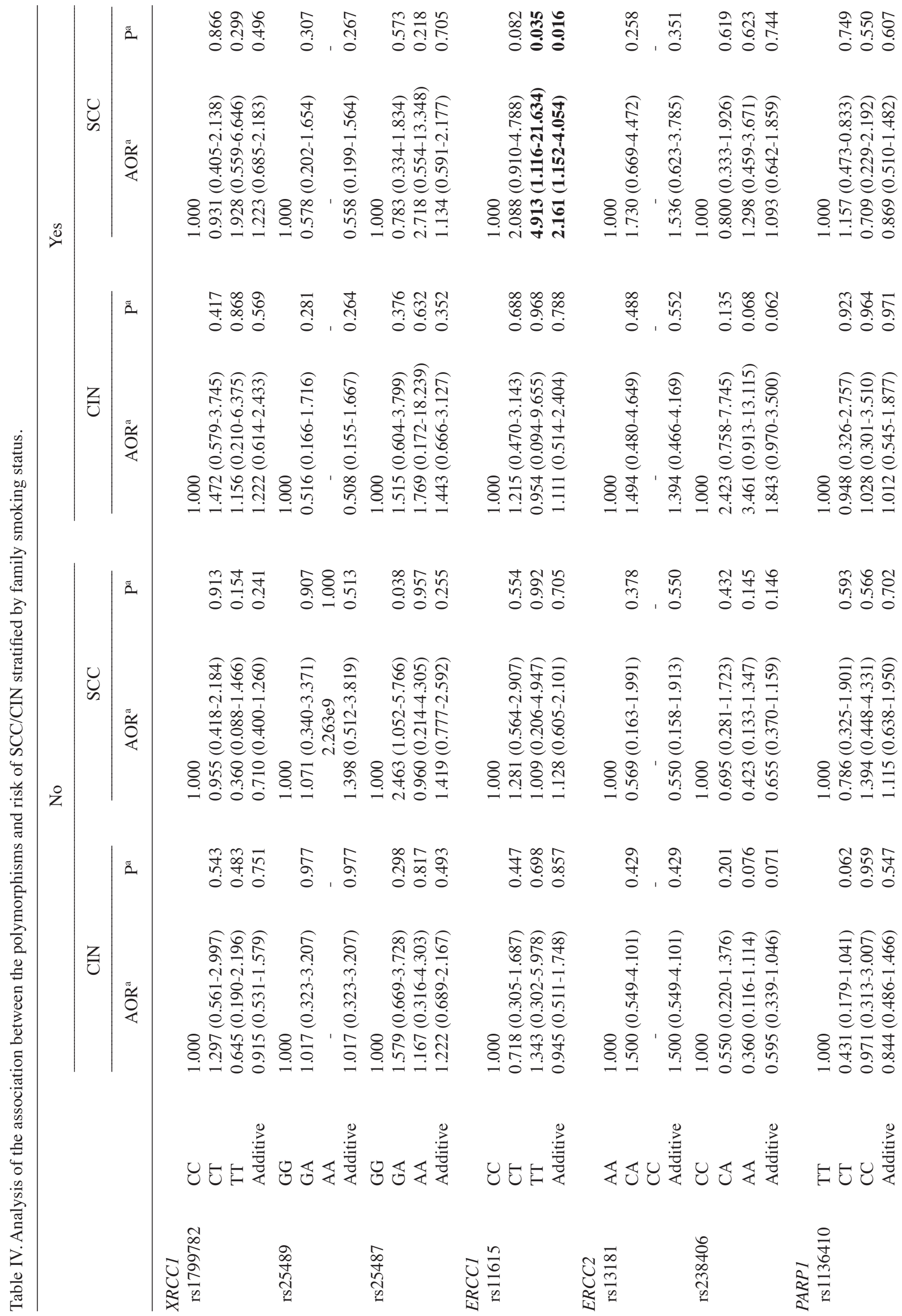




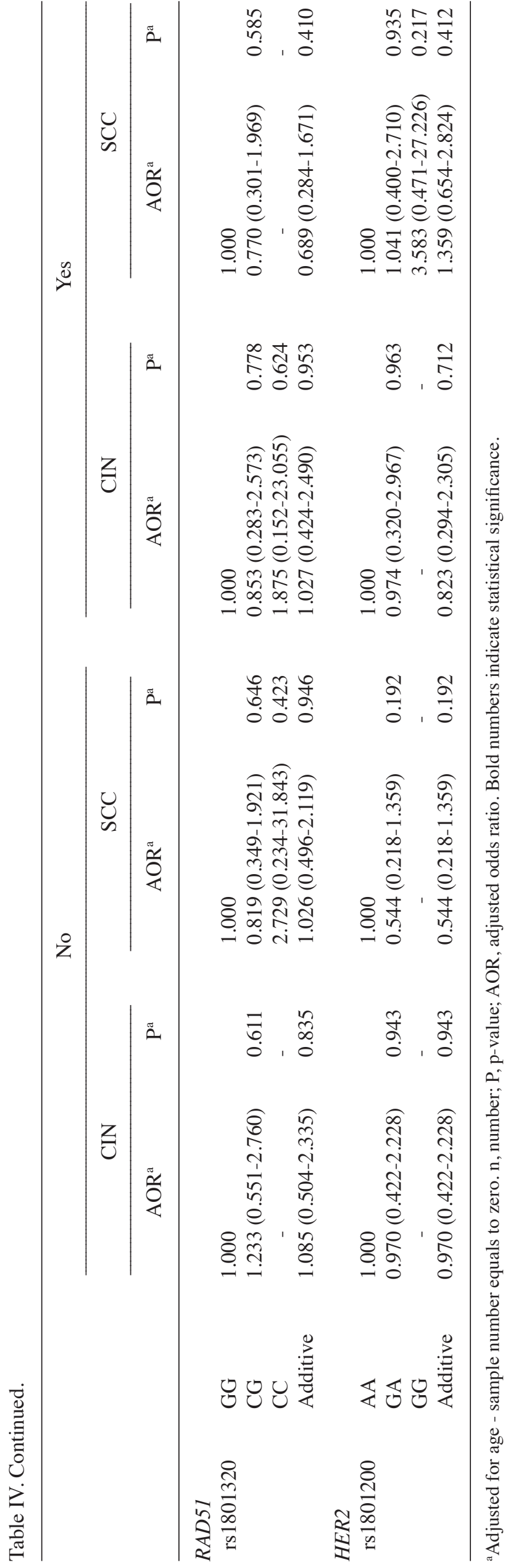

at first childbirth (Table II). Thus, stratification was performed by these three factors. Table IV shows the association using multivariate logistic regression analysis, stratified by family smoking status. Using the additive model where the family member smoking status was 'yes', the SNP ERCC1 118C >T had an increased risk of SCC (OR=2.800; 95\% CI, 1.314-5.968; $\mathrm{p}=0.008$ ). Meanwhile, ERCC2 $156 \mathrm{C}>\mathrm{A}$ tended to act as a risk factor for CIN under the additive model (OR=1.949; 95\% CI, 0.951-3.944; $\mathrm{p}=0.068$ ) if the family member smoking status was 'yes'. However, ERCC2 $156 \mathrm{C}>\mathrm{A}$ tended to be a protective factor for CIN under the additive model $(\mathrm{OR}=0.616$; 95\% CI, $0.347-1.095 ; \mathrm{p}=0.099)$ if the family member smoking status was 'no'. The different effects of the ERCC2 $156 \mathrm{C}>\mathrm{A}$ polymorphism between CIN and SCC suggest that its function may depend on exposure to tobacco smoke.

Among women having their first intercourse after the age of 22, there was no significant association for CIN using multivariate logistic regression analysis (Table V). However, the additive model showed that $R A D 51 \quad 135 \mathrm{G}>\mathrm{C}(\mathrm{OR}=0.359 ; 95 \%$ CI, 0.138-0.934; $\mathrm{p}=0.036)$ and HER2 655A $>\mathrm{G}(\mathrm{OR}=0.309$; 95\% CI, 0.098-0.972; $\mathrm{p}=0.045$ ) may be protective factors for SCC. In the subgroup who had their first intercourse before age 22, XRCC1 280G $>$ A showed a protective effect for SCC $(\mathrm{OR}=0.228 ; 95 \% \mathrm{CI}, 0.058-0.900 ; \mathrm{p}=0.035)$ under the additive model. Meanwhile, $R A D 51135 \mathrm{G}>\mathrm{C}$ was related to increased susceptibility to CIN under the additive model $(\mathrm{OR}=4.246$; 95\% CI, 1.335-13.502; $\mathrm{p}=0.014)$.

Using the additive model, XRCC1 399G $>$ A increased susceptibility to CIN in the subgroup who first gave birth before age $22(\mathrm{OR}=4.459 ; 95 \% \mathrm{CI}, 1.139-17.453 ; \mathrm{p}=0.032)$, and $E R C C 1 \quad 118 \mathrm{C}>\mathrm{T}$ was found to be a risk factor for SCC $(\mathrm{OR}=1.884 ;$ 95\% CI, 1.088-3.264; $\mathrm{p}=0.024)$ among those who first gave birth after age 22 .

Interaction between SNPs and demographic factors. RAD51 $135 \mathrm{G}>\mathrm{C}$ decreased the CIN risk in combination with first intercourse at a later age $(\mathrm{OR}=0.217$; 95\% CI, 0.059-0.798; $\mathrm{p}=0.021$ ), and increased CIN risk in combination with a greater number of sexual partners $(\mathrm{OR}=12.260 ; 95 \% \mathrm{CI}$, 2.874-52.305; p=0.001). ERCC2 $156 \mathrm{C}>\mathrm{A}$ increased the CIN risk in combination with family smoking status $(\mathrm{OR}=2.639$; 95\% CI, 1.157-6.020; $\mathrm{p}=0.021$ ).

HER2 $655 \mathrm{~A}>\mathrm{G}$ and $R A D 51$ 135G $>\mathrm{C}$ decreased the $\mathrm{SCC}$ risk when combined with first intercourse at a later age $(\mathrm{OR}=0.179 ; 95 \% \mathrm{CI}, 0.041-0.790 ; \mathrm{p}=0.023$; and $\mathrm{OR}=0.250$; 95\% CI, 0.070-0.893; $\mathrm{p}=0.033$; respectively). When combined with alcohol consumption, XRCC1 280G $>$ A increased the SCC risk $(\mathrm{OR}=7.117$; 95\% CI, 1.274-39.754; $\mathrm{p}=0.025)$.

\section{Discussion}

DNA repair genes have been frequently studied as significant determinants of cancer risk. Associations between SNPs in these genes and various types of cancer have been well documented but the picture remains complex, with often inconsistent data pointing to both increased and decreased risks (16-19). An association between the SNP XRCC1 Arg399Gln G>A and an increased susceptibility to cervical cancer has been shown in the Japanese population (20), in contrast to a decreased risk, but an increased persistence of HPV infection, in a population 


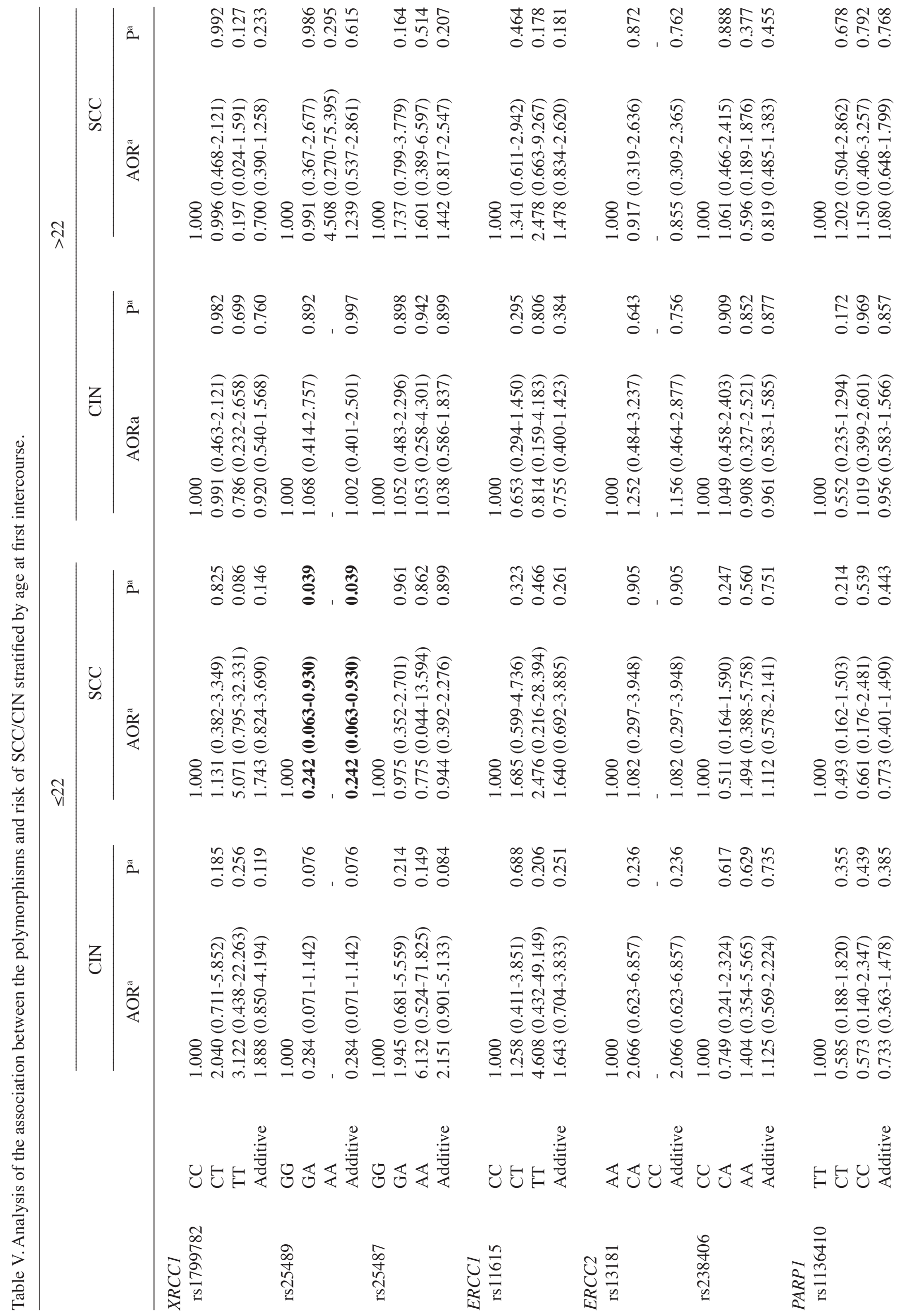


in Costa Rica (21). These data have been partially confirmed in this study where we observed an association between $\mathrm{XRCCl}$ Arg399Gln G>A and an increased CIN risk among women who first gave birth before the age of 22. However, other changes in XRCC1, such as XRCC1 Arg194Trp C $>\mathrm{T}$ showed no significant association with CIN/SCC, and among women who had their first intercourse before 22 years of age, there was a significant association between $X R C C 1 \mathrm{Arg} 280 \mathrm{His} \mathrm{G}>\mathrm{A}$ and a decreased susceptibility to SCC. Although no previous study has reported an association between alcohol consumption and cervical cancer, we observed an interaction between $\mathrm{XRCCl}$ $280 \mathrm{G}>\mathrm{A}$ and alcohol consumption $\left(\mathrm{p}_{\text {interaction }}<0.05\right)$, which may suggest that alcohol is involved in the development of cervical cancer.

The enzyme PARP1 (encoded by the gene of the same name) plays a role in repairing single-stranded DNA breaks. The PARPI Val762Ala $\mathrm{T}>\mathrm{C}$ polymorphism located in the catalytic domain has been shown to interact with XRCC1. In vitro, this polymorphism markedly reduces the enzymatic activity of $P A R P 1$, and has also been linked to cancer susceptibility (22). An increased risk of smoking-related lung cancer has also been reported (23). There are no previous reports evaluating the correlation of PARPI Val762Ala $\mathrm{T}>\mathrm{C}$ with cervical cancer as yet. Our analysis showed no significant association between the polymorphism and CIN/SCC risk.

The proteins, ERCC1 and ERCC2. are two of 16 proteins involved in NER systems, where they help to excise lesions from the DNA strand $(11,24)$. The proteins are encoded by the genes $E R C C 1$ and $E R C C 2$, respectively. In ERCC1, a polymorphism at $E R C C 1118 \mathrm{C}>\mathrm{T}$ has been shown to decrease the rate of mRNA translation to the protein (25). It is possible that a decreased level of ERCC1 mRNA expression influences the repair efficiency of DNA damage, which then contributes to cancer susceptibility. Studies have also shown an association between the polymorphism and malignancies such as lung, ovarian and colorectal cancer (26-29), although no previous association with cervical cancer has been shown. Our study showed that ERCCl $118 \mathrm{C}>\mathrm{T}$ may be a potential risk factor for SCC. Among the Chinese population, a homozygous CC polymorphism in ERCC2 at position $751 \mathrm{~A}>\mathrm{C}$ is related to a decreased DNA repair capacity in patients with lung cancer (30). In addition, there are data linking an ERCC2 polymorphism and glioblastoma (31). Our data indicate that $E R C C 2$ $751 \mathrm{~A}>\mathrm{C}$ and $E R C C 2156 \mathrm{C}>\mathrm{A}$ have no significant association in CIN/SCC. Furthermore, among women who first gave birth after 22 years of age, $E R C C l 118 \mathrm{C}>\mathrm{T}$ may be a risk factor for SCC.

The association between cervical cancer and smoking (and second-hand smoke) has already been established (7,32). The hypothesis is that the carcinogens in smoke initiate DNA damage, and then activate the DNA repair process; with polymorphisms in the DNA repair genes either increasing or decreasing the risk of cancer in the areas affected. In the case of cervical cancer, it is thought that smoke may have a directly carcinogenic effect by acting through the polycyclic aromatic hydrocarbon-DNA adduct in the cervix (33). When we looked at associations between family smoking status and SNPs, we found that $E R C C 1 \quad 118 \mathrm{C}>\mathrm{T}$, a potential risk factor for SCC, became more significantly associated with this outcome in women who live with family members who smoke. 


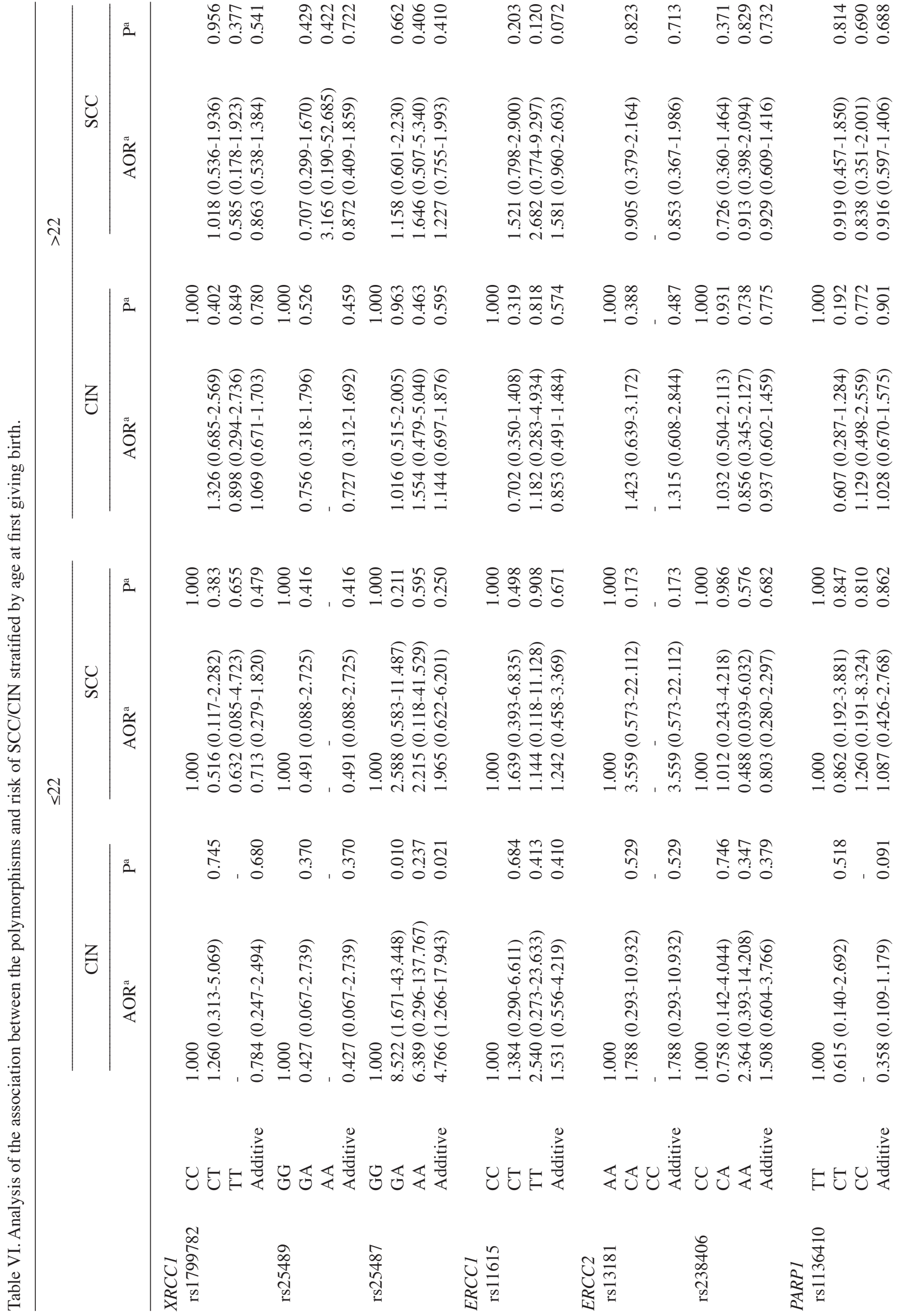




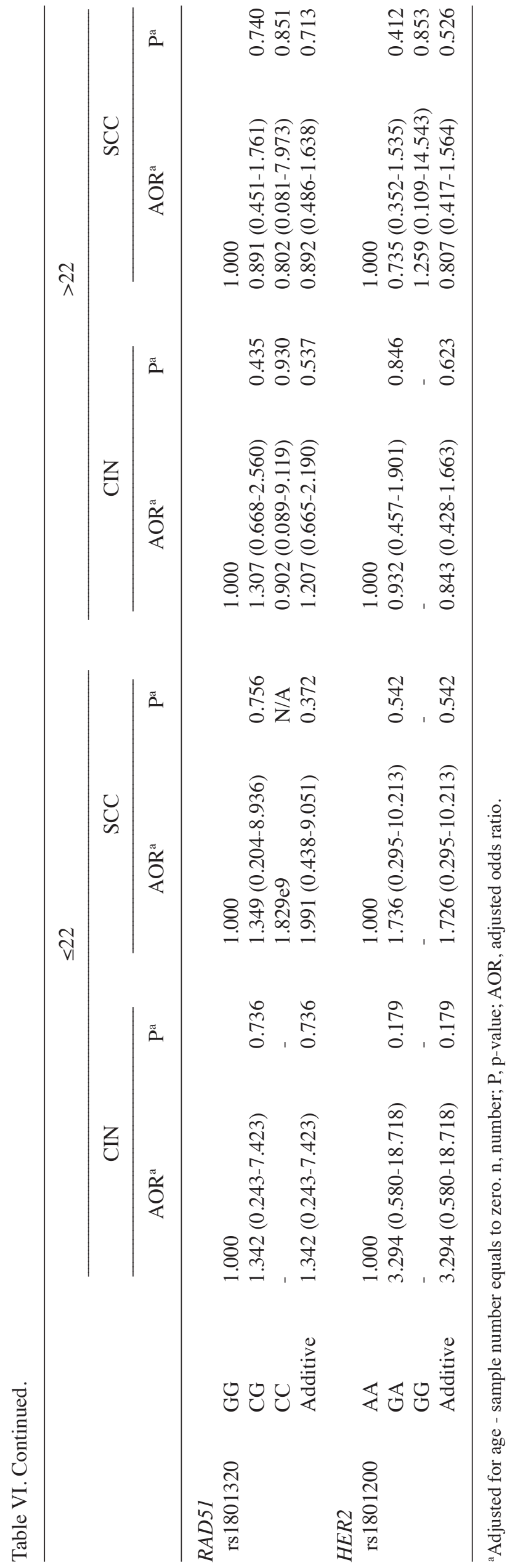

Although not statistically significant, ERCC2 156C $>$ A tended to be a risk factor among patients who have smoking family members, but tended to play a protective role in women whose families did not smoke. Tsai et al (32) previously showed that non-smoking women exposed to second-hand cigarette smoke had a significantly greater risk of developing CIN than unexposed non-smokers. Our data indicate that ERCC2 156C >A may play a role in the association between second-hand smoke and CIN.

The gene RAD51 plays a significant role in DNA repair of double-strand breaks via HR (34). Previous studies, although not looking at functional evidence, have shown that the polymorphism $R A D 51 \quad 135 \mathrm{G}>\mathrm{C}$ is related to breast cancer susceptibility (35). No RAD51 polymorphisms related to cervical cancer have been reported as yet. In this study, we observed that RAD51 $135 \mathrm{G}>\mathrm{C}$ may increase the risk of CIN in women who first had intercourse before the age of 22, but may be a protective factor for SCC in women who first had intercourse after the age of 22. Studies examining SNPs in HER 2 have mostly focused on HER $2655 \mathrm{~A}>\mathrm{G}$ in breast cancer (36), and no previous association has been shown in cervical cancer. In our analysis, HER 2 655A $>\mathrm{G}$ showed a decreased susceptibility to SCC in women who had first intercourse after the age of 22.

The interaction analysis in our study shows a consistent result with epidemiological data of cervical cancer. Women who have multiple sexual partners or a younger age at first sexual intercourse had a significantly higher risk of HPV infection (3) as well as an increased risk of cervical cancer (37). While our study indicates that polymorphisms in HER2 $655 \mathrm{~A}>\mathrm{G}$ and $R A D 51135 \mathrm{G}>\mathrm{C}$ and the age of first intercourse are related, it is worth noting that the age we used as a cut-off ( 22 years) is an arbitrary age that is open to some debate. There is evidence that in certain countries as many as $50 \%$ of women have their first intercourse between the ages of 13 and 19 years (37). Altering the age cut-off in our interaction analyses may affect the outcome and correlations between cervical cancer and the selected SNPs, and these analyses will need to be performed before any more firm conclusions can be drawn.

It is also worth noting that the sample size of our study was relatively small, which limits the statistical power, and, hence, the conclusions that may be drawn. Other studies examining associations in other types of cancer, such as lung or breast cancer have recruited larger numbers of patients, and this larger number of data points has enhanced the robustness of the findings. Cervical cancer patients however, are fewer in number compared with other types of cancer, and therefore we were limited as to the number of patients we could recruit to our study. Our study of 154 patients (82 carcinomas and 72 CINs) compares favorably with other recently published case-control studies in the same geographical area (38-40), but clearly there is a need for further research with larger sample sizes across diverse populations.

In addition, the data presented in this study were gained using an additive genetic model. Although the additive and dominant models are often highly correlated, there is debate as regards which is the most appropriate, and there are also cases where these tests are not appropriate, particularly if testing traits that turn out to be recessive (41). Further explo- 
ration of different models is required, particularly if larger sample sizes are used.

In conclusion, this is the first association study between cervical cancer and SNPs in ERCC1, ERCC2, RAD51 and $H E R 2$. Interaction analysis suggests that sexual behavior, second-hand smoke and alcohol consumption are co-factors combined with SNPs, and further research is required to confirm these findings.

\section{Acknowledgements}

This study was supported by the Shanghai Municipal Health Bureau Program 2006108 and the Shanghai Hongkou District Health Bureau Program 0601-03.

\section{References}

1. Kitchener HC, Castle PE and Cox JT: Achievements and limitations of cervical cytology screening. Vaccine 24: 63-70, 2006.

2. Valdespino VM and Valdespino VE: Cervical cancer screening: State of the art. Curr Opin Obstet Gynecol 18: 35-40, 2006.

3. Shi JF, Qiao YL, Smith JS, et al: Epidemiology and Prevention of Human Papillomavirus and Cervical Cancer in China and Mongolia. Vaccine 26: M53-M59, 2008.

4. Walboomers JMM, Jacobs MV, Manos MM, et al: Human papillomavirus is a necessary cause of invasive cervical cancer worldwide. J Pathol 189: 12-19, 1999.

5. Hausen HZ: Viruses in Human Cancers. Science 254: 1167-1173, 1991.

6. Giuliano AR, Harris R, Sedjo RL, et al: Incidence, prevalence, and clearance of type-specific human papillomavirus infections: The young women's health study. J Infect Dis 186: 462-469, 2002

7. Winkelstein W: Smoking and cervical cancer - current status: a review. Am J Epidemiol 131: 945-957, 1990.

8. Simons AM, Phillips DH and Coleman DV: Damage to DNA in cervical epithelium related to smoking tobacco. BMJ 306: 1444-1448, 1993.

9. Maser RS and DePinho RA: Connecting chromosomes, crisis, and cancer. Science 297: 565-569, 2002.

10. Jackson SP and Bartek J: The DNA-damage response in human biology and disease. Nature 461: 1071-1078, 2009.

11. Mu D, Park CH, Matsunaga T, Hsu DS, Reardon JT and Sancar A: Reconstitution of human DNA-repair excision nuclease in a highly defined system. J Biol Chem 270: 2415-2418, 1995.

12. Smith TR, Levine EA, Freimanis RI, et al: Polygenic model of DNA repair genetic polymorphisms in human breast cancer risk. Carcinogenesis 29: 2132-2138, 2008.

13. Schreiber V, Dantzer F, Ame JC and de Murcia G: Poly(ADPribose): novel functions for an old molecule. Nat Rev Mol Cell Biol 7: 517-528, 2006.

14. Li SX, Sjolund A, Harris L and Sweasy JB: DNA repair and personalized breast cancer therapy. Environ Mol Mutagen 51: 897-908, 2010.

15. Manuguerra M, Saletta F, Karagas MR, et al: XRCC3 and XPD/ ERCC2 single nucleotide polymorphisms and the risk of cancer: A HuGE review. Am J Epidemiol 164: 297-302, 2006.

16. Xing DY, Qi J, Miao XP, Lu WF, Tan W and Lin DX: Polymorphisms of DNA repair genes XRCC1 and XPD and their associations with risk of esophageal squamous cell carcinoma in a Chinese population. Int J Cancer 100: 600-605, 2002.

17. Huang WY, Gao YT, Rashid A, et al: Selected base excision repair gene polymorphisms and susceptibility to biliary tract cancer and biliary stones: a population-based case-control study in China. Carcinogenesis 29: 100-105, 2008.

18. Shen HB, Xu YC, Qian Y, et al: Polymorphisms of the DNA repair gene $\mathrm{XRCCl}$ and risk of gastric cancer in a Chinese population. Int J Cancer 88: 601-606, 2000.

19. Loizidou MA, Michael T, Neuhausen SL, et al: Genetic polymorphisms in the DNA repair genes XRCC1, XRCC2 and XRCC 3 and risk of breast cancer in Cyprus. Breast Cancer Res Treat 112: 575-579, 2008.
20. Niwa $\mathrm{Y}$, Matsuo K, Ito $\mathrm{H}$, et al: Association of XRCC1 Arg399Gln and OGG1 Ser326Cys polymorphisms with the risk of cervical cancer in Japanese subjects. Gynecol Oncol 99: 43-49, 2005.

21. Wang SS, Bratti MC, Rodriguez AC, et al: Common variants in immune and DNA repair genes and risk for human papillomavirus persistence and progression to cervical cancer. J Infect Dis 199: 20-30, 2009.

22. Wang XG, Wang ZQ, Tong WM and Shen Y: PARP1 Val762Ala polymorphism reduces enzymatic activity. Biochem Biophys Res Commun 354: 122-126, 2007.

23. Zhang XM, Miao XP, Liang G, et al: Polymorphisms in DNA base excision repair genes ADPRT and XRCC1 and risk of lung cancer. Cancer Res 65: 722-726, 2005.

24. Mu D, Hsu DS and Sancar A: Reaction mechanism of human DNA repair excision nuclease. J Biol Chem 271: 8285-8294, 1996.

25. Yu JJ, Mu CJ, Lee KB, et al: A nucleotide polymorphism in ERCC1 in human ovarian cancer cell lines and tumor tissues. Mutat Res 382: 13-20, 1997.

26. Kang S, Ju W, Kim JW, et al: Association between excision repair cross-complementation group 1 polymorphism and clinical outcome of platinum-based chemotherapy in patients with epithelial ovarian cancer. Exp Mol Med 38: 320-324, 2006.

27. Park DJ, Zhang W, Stoehlmacher J, Tsao-Wei D, Groshen S, Gil J, Yun J, Sones E, Mallik N and Lenz HJ: ERCC1 gene polymorphism as a predictor for clinical outcome in advanced colorectal cancer patients treated with platinum-based chemotherapy. Clin Adv Hematol Oncol 1: 162-166, 2003.

28. Suk R, Gurubhagavatula S, Park S, et al: Polymorphisms in ERCC1 and grade 3 or 4 toxicity in non-small cell lung cancer patients. Clin Cancer Res 11: 1534-1538, 2005.

29. Zhou W, Liu G, Park S, et al: Gene-smoking interaction associations for the ERCC1 polymorphisms in the risk of lung cancer. Cancer Epidemiol Biomarkers Prev 14: 491-496, 2005.

30. Yin JY, Vogel U, Ma YG, Guo L, Wang HW and Qi R: Polymorphism of the DNA repair gene ERCC2 Lys751Gln and risk of lung cancer in a northeastern Chinese population. Cancer Genet Cytogenet 169: 27-32, 2006.

31. McKean-Cowdin R, Barnholtz-Sloan J, Inskip PD, et al: Associations between polymorphisms in DNA repair genes and glioblastoma. Cancer Epidemiol Biomarkers Prev 18: 1118-1126, 2009.

32. Tsai HT, Tsai YM, Yang SF, et al: Lifetime cigarette smoke and second-hand smoke and cervical intraepithelial neoplasma community-based case-control study. Gynecol Oncol 105: 181-188, 2007.

33. Hellberg D, Valentin J and Nilsson S: Smoking as risk factor in cervical neoplasia. Lancet 2: 1497-1497, 1983.

34. Galkin VE, Esashi F, Yu X, Yang SX, West SC and Egelman EH: BRCA2 BRC motifs bind RAD51-DNA filaments. Proc Natl Acad Sci USA 102: 8537-8542, 2005.

35. Jara L, Acevedo ML, Blanco R, et al: RAD51 135G $>$ C polymorphism and risk of familial breast cancer in a South American population. Cancer Genet Cytogenet 178: 65-69, 2007.

36. Xie DW, Shu XO, Deng ZL, et al: Population-based, case-control study of HER 2 genetic polymorphism and breast cancer risk. J Natl Cancer Inst 92: 412-417, 2000.

37. Louie KS, de Sanjose S, Diaz M, et al: Early age at first sexual intercourse and early pregnancy are risk factors for cervical cancer in developing countries. Br J Cancer 100: 1191-1197, 2009.

38. Han SS, Cho EY, Lee TS, et al: Interleukin-12 p40 gene (IL12B) polymorphisms and the risk of cervical cancer in Korean women. Eur J Obstet Gynecol Reprod Biol 140: 71-75, 2008.

39. Kohaar I, Thakur N, Salhan S, et al: TNF alpha-308G/A polymorphism as a risk factor for HPV associated cervical cancer in Indian population. Cell Oncol 29: 249-256, 2007.

40. Tong SY, Lee JM, Song ES, et al: Functional polymorphism in manganese superoxide dismutase and antioxidant status: Their interactions on the risk of cervical intraepithelial neoplasia and cervical cancer. Gynecol Oncol 115: 272-276, 2009.

41. Lettre G, Lange C and Hirschhorn JN: Genetic model testing and statistical power in population-based association studies of quantitative traits. Genet Epidemiol 31: 358-362, 2007. 